\title{
Validation of large-scale particle image velocimetry to acquire free-surface flow fields in vegetated rivers
}

\author{
Stéphan Creëlle, Rebeca Roldan, Anke Herremans, Dieter Meire, Kerst Buis, \\ Patrick Meire, Tomas Van Oyen, Tom De Mulder \& Peter Troch
}

To cite this article: Stéphan Creëlle, Rebeca Roldan, Anke Herremans, Dieter Meire, Kerst Buis, Patrick Meire, Tomas Van Oyen, Tom De Mulder \& Peter Troch (2016): Validation of large-scale particle image velocimetry to acquire free-surface flow fields in vegetated rivers, Journal of Applied Water Engineering and Research, DOI: 10.1080/23249676.2016.1251856

To link to this article: http://dx.doi.org/10.1080/23249676.2016.1251856

曲 Published online: 10 Nov 2016.

Submit your article to this journal $\pi$

View Crossmark data $\nearrow$ 


\title{
Validation of large-scale particle image velocimetry to acquire free-surface flow fields in vegetated rivers
}

\author{
Stéphan Creëlle ${ }^{\mathrm{a} *}$, Rebeca Roldan $^{\mathrm{a}}$, Anke Herremans $^{\mathrm{a}}$, Dieter Meire ${ }^{\mathrm{a}, \mathrm{b}}$, Kerst Buis $^{\mathrm{c}}$, Patrick Meire $^{\mathrm{c}}$, Tomas Van Oyen ${ }^{\mathrm{a}, \mathrm{b}}$, \\ Tom De Mulder ${ }^{\mathrm{a}}$ and Peter Troch ${ }^{\mathrm{a}}$ \\ ${ }^{a}$ Hydraulics Laboratory, Department of Civil Engineering, Ghent University, Ghent, Belgium; ${ }^{b}$ Flanders Hydraulics Research, \\ Antwerp, Belgium; ' Department of Biology, Research group 'Ecosystem Management', University of Antwerp, Antwerp, Belgium
}

(Received 15 July 2015; accepted 8 September 2016)

\begin{abstract}
The reliability of large-scale particle image velocimetry (LSPIV) methodology to measure a 2D surface velocity field in a vegetated lowland stream is evaluated. To this end, measurements of the free-surface flow field obtained with LSPIV are compared with measurements with an electromagnetic current meter (ECM) close to the surface at four different locations. The measurements were performed monthly, allowing the evaluation of the LSPIV measurements in relation to different vegetated conditions. The difference observed between the mean velocities measured with ECM and LSPIV remains low in winter, whereas an increase is observed in summer. Inappropriate particle seeding density and unsteadiness of the flow are the main sources of LSPIV reliability reduction. Nonetheless, the seasonal average frequency of reliable LSPIV measurements is $97 \%, 95 \%$ and $78 \%$ in winter, spring and summer, respectively. The results illustrate that LSPIV is an inexpensive methodology, which provides high-resolution and reliable data to study the flow-field distribution in vegetated rivers, provided some considerations are taken into account to deal with the added complexity of the vegetation presence and the field conditions.
\end{abstract}

Keywords: image techniques; large-scale particle image velocimetry; validation; field application; vegetated river; flow patterns

\section{Introduction}

Over the past decade, interest in the influence of vegetation on fluvial processes has significantly increased. Flowvegetation interaction has proven to be of major importance in the hydrodynamic behavior of natural streams and rivers (Carollo et al. 2002; Sukhodolov \& Sukhodolova 2010). In recent years, many efforts have focused on developing widely applicable methods of predicting flow resistance in vegetated channels (Sand-Jensen \& Pedersen 1999; Stephan \& Gutknecht 2002; Jarvela 2005; Nikora et al. 2008; De Doncker et al. 2009; Poggi et al. 2009; Folkard 2011). In fact, plant-flow interaction and their influence on the resistance coefficients is a long-standing problem in hydraulic research (Franklin et al. 2008; Nikora et al. 2008).

Laboratory experiments have shown the complexity of predicting the effect of different macrophyte distribution patterns on the hydraulic resistance of lowland rivers (Bal et al. 2011). Presently, 2D numerical models have the promising capacity of accurately and explicitly quantifying spatial variations and combinations of flow patterns (Leu et al. 2008; Van Oyen 2012). The ability to model channel flows in vegetated rivers with a wide range of vegetation properties (species, abundance and morphology) and water depths is improving. Nevertheless, more insight is needed, particularly when the plants are randomly distributed within the channel (Green 2005). To this end, a great amount of field data from different flow and vegetation conditions is necessary to validate and calibrate such models. Moreover, direct studies of the naturally occurring ecohydraulic systems are valuable to understand the fundamental processes behind the ecosystem as a whole. Application of large-scale particle image velocimetry (LSPIV) can provide a high-resolution velocity field with limited effort, that can be used to quantify transport of floating material such as propagules, insects, floating seeds. Furthermore, detailed velocity fields can give insights into important gradients in the flow, caused by e.g. the wake of emergent vegetation, that gives rise to the formation of coherent structures, which can influence the exchange of nutrients, sediments, etc.

Conventional techniques have been extensively developed to obtain reliable hydraulic measurements. De Doncker et al. (2008) discussed the suitability of several techniques and instruments to perform hydraulic measurements under laboratory and field conditions, and the electromagnetic current meter (ECM) was recommended to perform measurements in vegetated lowland rivers. An

*Corresponding author. Email: stephan.creelle@ugent.be 
ECM has no moving parts which can interfere with the vegetation. The estimated uncertainty of the ECM is as low as $0.5 \%$, with a preference for velocities smaller than $2.5 \mathrm{~m} / \mathrm{s}$. The main drawback, however, is the use of single-point measurements. Because of this, obtaining a spatial characterization of the planimetric flow distribution is highly expensive and labor intensive (Muste et al. 2008).

This paper investigates the application of Particle Image Velocimetry (PIV) to obtain high-resolution surface flow velocity fields at reach scale. The technique measures the displacement of particles between two consecutive images, recorded at known time intervals. To obtain the velocity, the resulting displacement vector is divided by the time (Adrian 1991). More recently,PIV was adapted to measure surface velocities at large scales in the field without the need for artificial illumination. This procedure is named LSPIV (Fujita et al. 1998).

In recent years, LSPIV has been tested to obtain the complete flow field for many different applications, e.g. flood events, monitoring morphological changes after reservoir release, aquatic habitat mapping and discharge calculation (Bradley et al. 2002; Meselhe et al. 2004; Smith et al. 2005; Jodeau et al. 2008; Kantoush et al. 2011). Indeed, the scale of application can be adapted, depending on the field of interest. LSPIV has proven to be a reliable method to obtain horizontal flows over the area of a few squared meters (Jodeau et al. 2008) or even to measure the velocity field of an entire river stretch of hundreds of meters in length (Fujita \& Hino 2003). Therefore, LSPIV has a significant advantage over classical point measurement devices, since it can provide data over an extensive spatial domain with a limited measurement effort. Moreover, LSPIV measures the full magnitude of the velocities regardless their orientation (Smith et al. 2005), which is another advantage of LSPIV in complex flow pattern conditions. However, to date, the reliability of LSPIV in obtaining surface velocity fields in vegetated rivers has not been tested. Vegetation presence complicates LSPIV measurements because of several reasons. Physical obstruction of the flow can catch the particles, giving rise to inadequate seeding downstream of the vegetation, but also to incorrect measurements at the location of the blocked particles. Furthermore, the vegetation causes the formation of large (local) velocity gradients and of turbulent structures, presenting more challenging conditions for the LSPIV processing. Lastly, the turbulent structures can cause boils of up- or down-welling water, again disturbing the particle seeding and reducing the LSPIV accuracy.

A rigorous uncertainty analysis of the surface velocity field is a complicated task for LSPIV (Kim et al. 2008), since the local error can vary from one grid point to another over an image. Furthermore, errors from different sources depend on each other, on the LSPIV configuration and on operating conditions. Comparison of LSPIV velocity measurements in field conditions with measurements obtained by a Doppler velocimeter revealed up to $35 \%$ error over the cross section (Kim et al. 2008).

The central goal of the manuscript is therefore to assess the reliability of LSPIV by means of the comparison with an ECM. The aim was not to establish a specific methodology for LSPIV measurements, but to describe a cost-time efficient methodology which enables the study of the surface velocity flow distribution in vegetated rivers.

\section{LSPIV methodology}

The underlying concept of LSPIV is to take a series of photos in quick succession in such a manner that the flow velocity can be inferred from the displacement of the tracers spread on the water surface. Hence, the correct approach depends mainly on the tracer material and the recording device. When sufficient natural particles are recognizable in the field and thus can be used as tracers, the use of artificial particles is not necessary (Hauet et al. 2008). Nevertheless, in absence of natural tracers, as in the current situation, seeding particles should be spread in the stream during the field measurements (Weitbrecht et al. 2002; Muste et al. 2004). Once the approach has been selected, it is necessary to follow the correct methodology. Each step has important parameters which should be adapted depending on the nature of the flow and field conditions. Figure 1 provides a flow chart of the entire methodology. Since LSPIV methodology has been

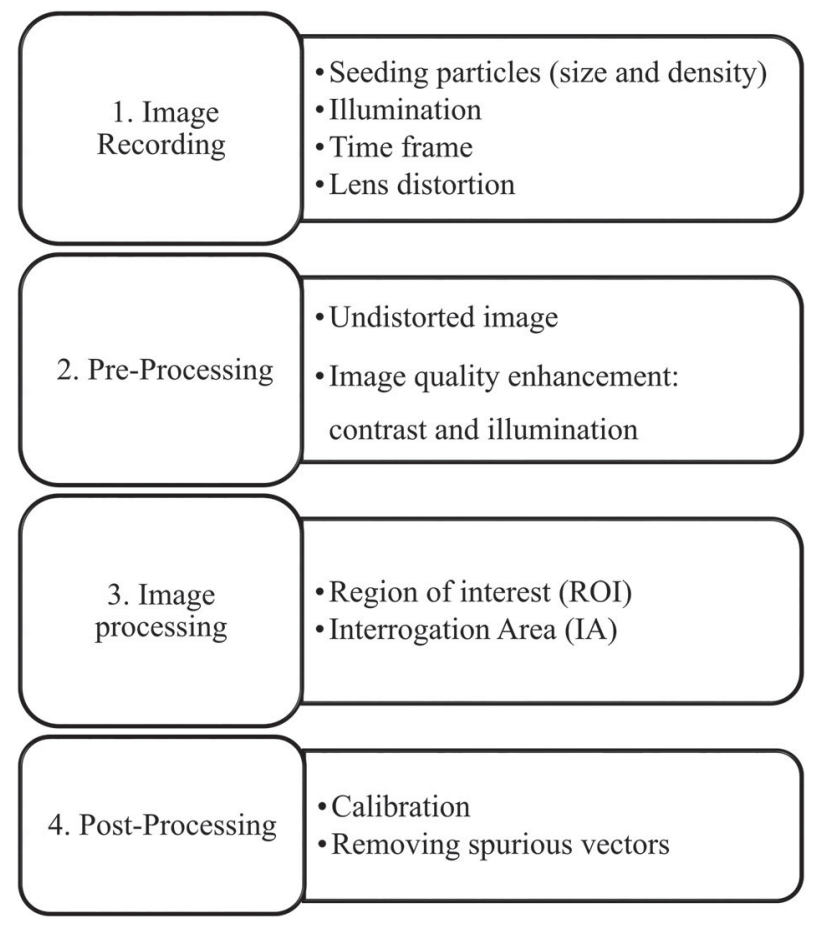

Figure 1. LSPIV flow chart with the four main steps and associated critical parameters. 
explained in detail (Fujita et al. 1998; Weitbrecht et al. 2002; Muste et al. 2011), only the parameters relevant to this experiment are discussed.

\section{Image recording}

In the current paper, images were recorded with a commercial camera (Nikon D300s and $11 \mathrm{~mm} \mathrm{f} / 2.8$ lens) because of the high resolution, low cost and easy accessibility. The Camera Control Pro 2 software was used to take pictures with a time interval of $0.14 \mathrm{~s}$. In this fast burst mode, the camera used had a storage capacity limit of 20 images. To obtain a larger amount of data, three consecutive time series were recorded from a fixed position leading to a total of 60 images. This drawback of the camera could be circumvented by using a (high frame rate) video camera instead of a photo camera (Bradley et al. 2002; Meselhe et al. 2004; Muste et al. 2008). During the image recording, the parameters controlling the visualization and illumination of the seeding particles are critical (Stanislas \& Monnier 1997). To be captured by the camera, the size of the seeding particle should be large enough to be represented by at least one pixel. The maximum resolution of the images depends on the relation between the size of the field of view and the inherent resolution of the camera. In this particular case, the resolution of the camera was $4288 \times 2848$ pixels to capture a field of view of $8.5 \mathrm{~m}$ (length) $\times 5.7 \mathrm{~m}$ (width), leading to an image resolution of $0.2 \mathrm{~cm}$ per pixel.

In order to improve the image quality and reduce the computational time required to process the images, it is highly advisable to maximize the contrast between the seeding particles and the background. However, the LSPIV recordings are performed outside in the field without artificial illumination. We experienced that a nonhomogeneous illumination, caused by glares and shadows appearing on the water surface significantly decreased the contrast. After testing several candidate tracer materials, white floating oatmeal of $0.5 \mathrm{~cm}$ diameter was selected as seeding material. During the image recording, the seeding particles were homogeneously distributed upstream of the river trying to cover the complete channel width. To obtain reliable results, an average of $10-30 \%$ of the area should be covered by the seeding particles (Meselhe et al. 2004).

The main drawbacks of optical techniques are the lens and perspective distortion. To correct the perspective distortion due to the angle between the optical axis of the camera and the plane of the image, orthorectification is required (Creutin et al. 2003; Muste et al. 2008). In this case, image orthorectification was avoided by placing the optical axis perpendicular to the field of view. However, the lens distortion is an inherent property of the recording technique which needs to be corrected for during the next step called pre-processing.

\section{Pre-processing}

In the present study, the Image Camera Calibration Toolbox for Matlab software (Bouguet 2010) was used to calibrate and remove the lens distortion. The negative effects of an inappropriate illumination were corrected by means of histogram equalization, with the main goal of enhancing the contrast between the particles and the background. The program used was GIMP 2 (GNU Image Manipulation Program). These procedures were automatically applied to all the images with similar illumination conditions. As a result of this procedure, the shadows and reflection in the image were removed and only the seeding particles, with a uniform pixel intensity remained in the image (see Figure 2(b)). Furthermore, the regions surrounding the seeded flow were masked during the image processing step saving substantial amount of computational time.

\section{Image processing}

The open-source software PIVlab v1.32 (Thielicke \& Stamhuis 2015) was used to perform the analysis of the image time series. One of the most critical parameters in the entire process is the dimension of the interrogation area (IA), which establishes the spatial resolution of the measurements. To obtain reliable results, the size of the IA should be selected depending on the number of seeding particles. The seeding density selected $(64 \times 64$ pixels $)$ had an average of more than 20 particles per AI, in agreement with Muste et al. (2004) who recommended four to eight seeding particles per IA.

Furthermore, the maximum particle displacement between two frames should be less than $50 \%$ of the IA (velocity/time interval $\leq 1 / 2$ IA side length) to minimize the loss of particles between two consecutive frames. Following Weitbrecht et al. (2002), we make use of an adaptive multipass since the velocity field conditions are not homogeneous. This multipass method improves the quality of the measurements by selecting up to three different sizes for the IA, and using the results of the processing step with larger IA as first estimates for the processing step with a smaller IA. Decreasing the size of the IA or increasing the number of IA sizes for the multipass increases the computational cost. A trial and error test is advisable to select the best combination of IA sizes. For instance, Figure 3 shows the surface velocity profile over a cross section obtained for different sizes and numbers of IA. We found that an IA of $32 \times 32$ pixels provided erroneous results as a consequence of particle loss between two consecutive frames. On the other hand, the results obtained with the larger IA $(500 \times 500$ pixels $)$ were accurate but did not achieve the desired resolution. Therefore, two IA sizes were selected with an area of $128 \times 128$ pixels and $64 \times 64$ pixels. As a result of the image processing, we obtained the instantaneous vector fields for 

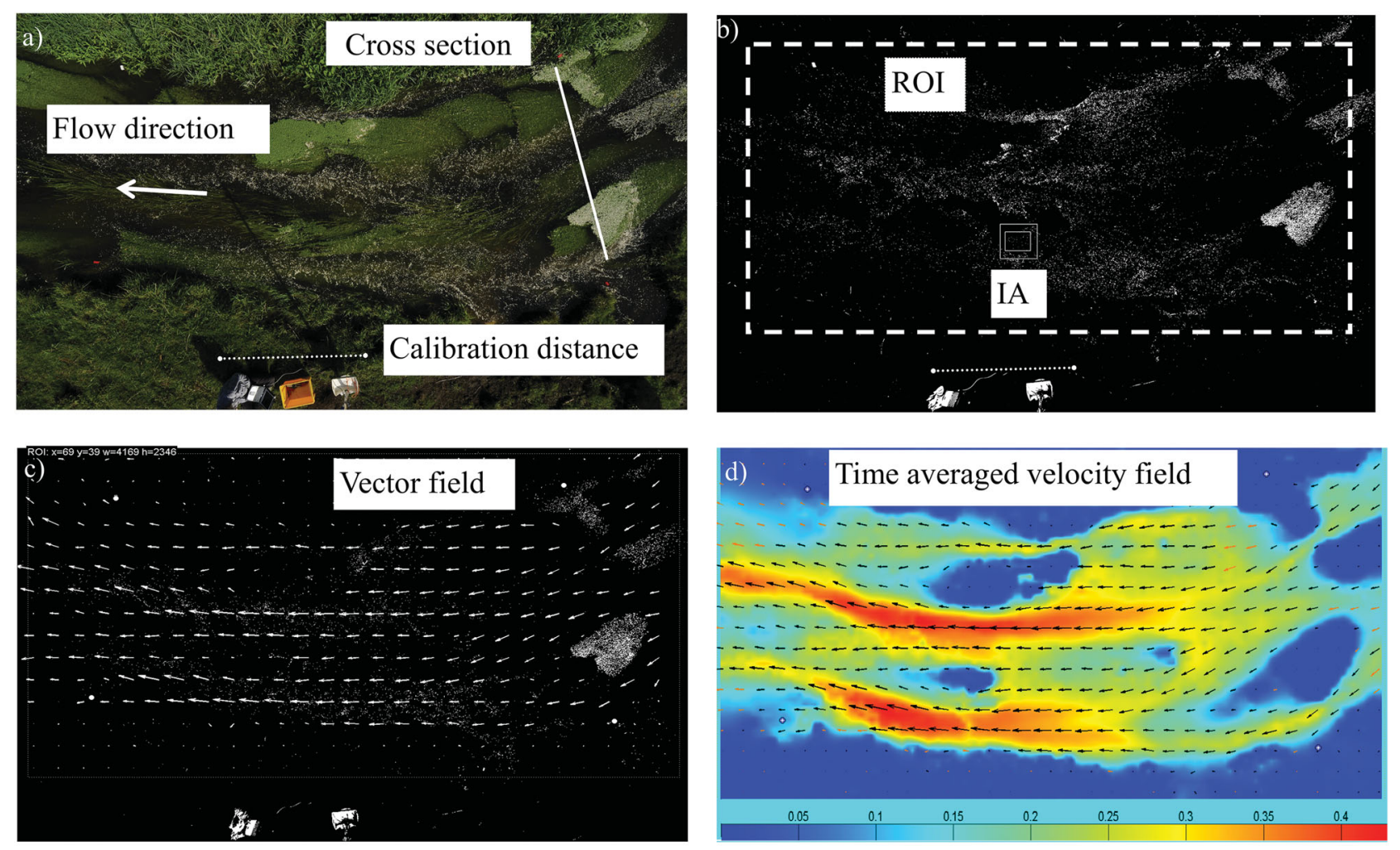

Figure 2. Illustration of the flow chart of LSPIV methodology (summer, Location 2). (a) Image recording: raw image of the field, covering $8.5 \mathrm{~m} \times 4.5 \mathrm{~m}$. (b) Pre-processed image, only the seeding particles are visible in the field. The AI utilized was $64 \times 64$ pixels, corresponding to a $12.8 \mathrm{~cm} \times 12.8 \mathrm{~cm}$ IA size. (c) Processed image with the instantaneous velocity vector field obtained in the ROI. (d) Post-processed image and resultant time-averaged velocity field, ranging from $0 \mathrm{~m} \mathrm{~s}^{-1}$ (blue) to $0.4 \mathrm{~m} \mathrm{~s}^{-1}$ (red).

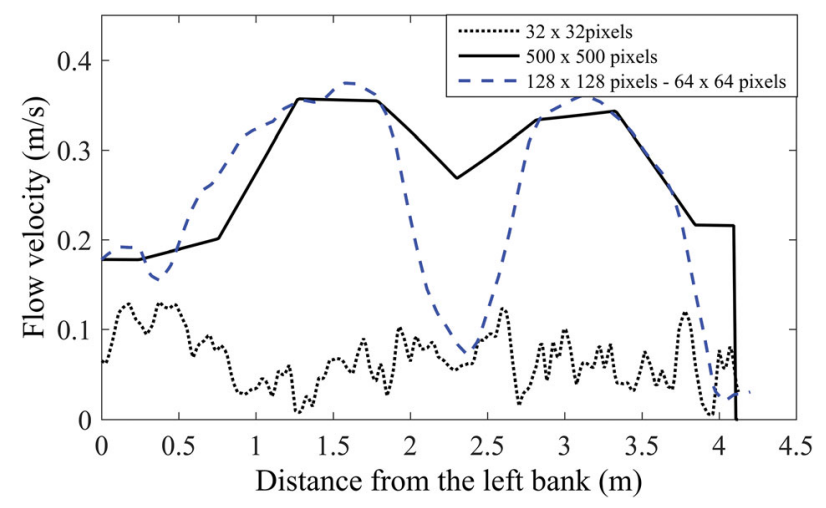

Figure 3. Averaged velocity obtained over one cross section for different sizes of interrogation areas (IA).

each pair of images for the region of interest (ROI) (Figure 2(c)).

\section{Post-processing}

Frequently, spurious vectors appear in the vector field after the image processing when the measurement conditions such as illumination or seeding density are not suitable.
To remove the spurious vectors, a post-processing step can be applied (e.g. vector validation). In the presented example, however, such a step was not deemed necessary since the main vector field showed no obvious spurious vectors.

Because of the flow disturbance due to the vegetation (and the banks), however, some areas in the field of view were not adequately seeded. In zones with floating or emergent vegetation, particles were obstructed and remained attached to the vegetation. This can be seen clearly in the images, and since in these zones the particles do not follow the flow velocities, these zones can be omitted from further analysis. Downstream of these zones, lower seeding densities are observed because of the lost particles. If the particle density is too low, resultant velocity vectors should not be used for analysis and should be also removed.

Finally, after the post-processing step, it is possible to visualize the instantaneous vector fields in pixels per frame. To obtain the displacement in $\mathrm{m} / \mathrm{s}$, it is necessary to calibrate the measurements by introducing a known distance between two points in the image (Figure 2(a)). Once the images time series are processed, the $2 \mathrm{D}$ free-surface velocity field can be calculated by averaging instantaneous vector fields over the complete time series of 60 images (Figure 2(d)). 


\section{Measuring location and methods}

The measurements presented were performed in the Zwarte Nete, a lowland river in the Scheldt catchment in north-east Belgium. The selected reach was $175 \mathrm{~m}$ long and had an average width of $4.5 \mathrm{~m}$ (Figure 4). The average discharge was $0.30 \mathrm{~m}^{3} \mathrm{~s}^{-1}$ in April and $0.25 \mathrm{~m}^{3} \mathrm{~s}^{-1}$ in August with peaks up to $0.45 \mathrm{~m}^{3} \mathrm{~s}^{-1}$. Water depth rarely exceeded $1 \mathrm{~m}$ and the maximum velocities measured were $0.45 \mathrm{~m} \mathrm{~s}^{-1}$. The stream was situated in undercut banks, which were about $40 \mathrm{~cm}$ above the water level, so the free surface was substantially shielded from the influence of wind. Measurement days were chosen not to follow any major rainfall, to limit the variability in boundary conditions during a measurement day. Upstream and downstream of the measurement reach, divers (i.e. submerged pressure transducers) were placed, confirming limited variation $( \pm 2 \mathrm{~cm})$ in water depth. Data on the average flow rate were available from an upstream weir, confirming only small variations in the flow rate during measurements.

There were four main species of vegetation encountered in the stream; Callitriche platycarpa, Myriphyllum spicatum, Elocea Canadensis and Sparganium emersum. During winter, no vegetation was present, while in spring, the prevailing species was $S$. emersum. The vegetation reached maximum density in summer, characterized by a patch matrix distribution with a wide range of heights and sizes.

To capture the annual variability of flow pattern distribution as a result of vegetation occurrence, monthly field campaigns were carried out at four locations (L1, L2, L3 and L4) from April to August (Figure 4). The LSPIV image recording was performed from the bank in a fixed position for each location. The camera was installed at the top of a $4 \mathrm{~m}$ mast with the optical axis positioned perpendicular to the field of view (Figure 4) while seeding particles were manually spread over the water surface.

During the field campaigns, stream velocity measurements were performed in parallel with the LSPIV image recording with an ECM (Valeport 2007, Model 801) previously calibrated in laboratory conditions. The ECM was selected over Acoustic Doppler Velocimeter (ADV) and propeller measurements for the recording of validation material, because of the issues of both other techniques in the presence of vegetation. Vegetation in the flow acts as an acoustic boundary, interfering with the measurement signal emitted by the ADV, and disturbing the measurements in the (near) presence of vegetation. Propeller measurements also directly suffer from vegetation presence, because the vegetation blocks the propeller movement, and inhibits any measurements. Since the interest of the LSPIV methodology as performed lies within the large flow scales, no high frequency information on the flow was required. Measurements close to and inside vegetation patches is, however, crucial for the overall performance in vegetated flow, and thus ECM measurements were chosen.

To perform the ECM measurements, one fixed cross section was selected in each location. On average, 10 measurements were performed along the width at each cross section with a horizontal spacing of $30 \mathrm{~cm}$ at $5 \mathrm{~cm}$ depth below the water surface. The ECM was kept stationary for at least $30 \mathrm{~s}$ with a frequency of $2 \mathrm{~Hz}$ to obtain the average ECM velocity at each point. To obtain discharge data, ECM measurements were taken at two more depths, and discharges were calculated with the velocity-area method.

The data provided by LSPIV allowed the study of the flow pattern distribution in the river under different vegetative growth conditions, with a high spatial resolution. The LSPIV method was evaluated through a direct comparison with the ECM mean velocities. Since the LSPIV spatial resolution was much higher than that of the ECM, each of the ECM measurements was compared with the nearest LSPIV measurement over the cross section.

The velocity and standard deviation (SD) for LSPIV and ECM were estimated, averaging the values of all the points included in each cross section. The SD designates the velocity variation over the cross section. The averaged discrepancy $d[\%]$ in each cross section (Equation (1)) shows the level of disagreement between the timeaveraged ECM-LSPIV measurements (Table 1).

$$
d=\frac{\left|V_{\mathrm{LSPIV}}-V_{\mathrm{ECM}}\right|}{\left|V_{\mathrm{ECM}}\right|} \times 100 .
$$

\section{Results}

From all data gathered, one month with characteristic vegetation for each season was selected; winter
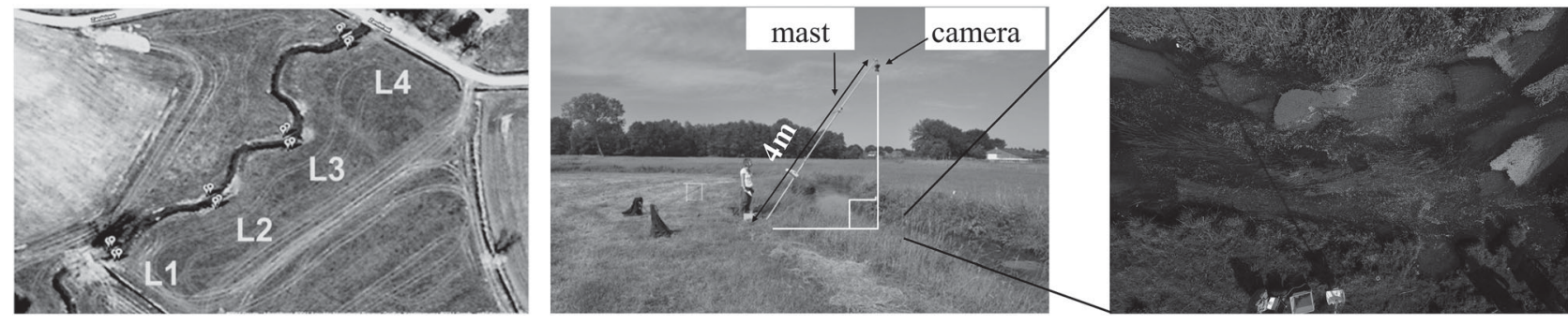

Figure 4. Study area of the river Zwarte Nete and location of the measurements; L1, L2, L3 and L4. LSPIV field measurements; installation of the mast and camera position. RGB- image and seeding particles captured by the camera. 
Table 1. LSPIV and ECM mean velocity, \% discrepancy $(d)$ and the corresponding SD calculated averaging the data of all the points within the stream channel for each location (L1, L2, L3 and L4) and season.

\begin{tabular}{|c|c|c|c|c|c|c|}
\hline \multirow[b]{4}{*}{ Season } & \multicolumn{6}{|c|}{ Location } \\
\hline & \multicolumn{3}{|c|}{ L1 } & \multicolumn{3}{|c|}{ L2 } \\
\hline & \multicolumn{2}{|c|}{$V \pm \mathrm{SD}(\mathrm{m} / \mathrm{s})$} & \multirow[b]{2}{*}{$d \pm \mathrm{SD}(\%)$} & \multicolumn{2}{|c|}{$V \pm \mathrm{SD}(\mathrm{m} / \mathrm{s})$} & \multirow[b]{2}{*}{$d \pm \mathrm{SD}(\%)$} \\
\hline & LSPIV & $\mathrm{ECM}$ & & LSPIV & $\mathrm{ECM}$ & \\
\hline Winter $(05 / 15 / 2012)$ & $0.276 \pm 0.015$ & $0.272 \pm 0.026$ & $5.9 \pm 4.8$ & $0.283 \pm 0.016$ & $0.302 \pm 0.027$ & $9.4 \pm 4.6$ \\
\hline Spring $(11 / 06 / 2012)$ & $0.300 \pm 0.019$ & $0.287 \pm 0.029$ & $9.3 \pm 10.8$ & $0.332 \pm 0.029$ & $0.334 \pm 0.023$ & $9.0 \pm 7.3$ \\
\hline Summer $(29 / 08 / 2012)$ & $0.178 \pm 0.035$ & $\begin{array}{c}0.183 \pm 0.020 \\
\text { L3 }\end{array}$ & $40.1 \pm 34.7$ & $0.186 \pm 0.026$ & $\begin{array}{c}0.128 \pm 0.0223 \\
\text { L4 }\end{array}$ & $34.5 \pm 33.8$ \\
\hline Winter $(05 / 15 / 2012)$ & $0.283 \pm 0.022$ & $0.364 \pm 0.018$ & $15.9 \pm 15.3$ & $0.265 \pm 0.093$ & $0.276 \pm 0.020$ & $7.9 \pm 6.0$ \\
\hline Spring $(11 / 06 / 2012)$ & $0.297 \pm 0.034$ & $0.285 \pm 0.026$ & $13.0 \pm 11.2$ & $0.278 \pm 0.042$ & $0.284 \pm 0.043$ & $12.1 \pm 11.6$ \\
\hline Summer $(29 / 08 / 2012)$ & $0.253 \pm 0.07$ & $0.244 \pm 0.020$ & $20.6 \pm 21.4$ & $0.128 \pm 0.078$ & $0.132 \pm 0.038$ & $20.8 \pm 18.6$ \\
\hline
\end{tabular}

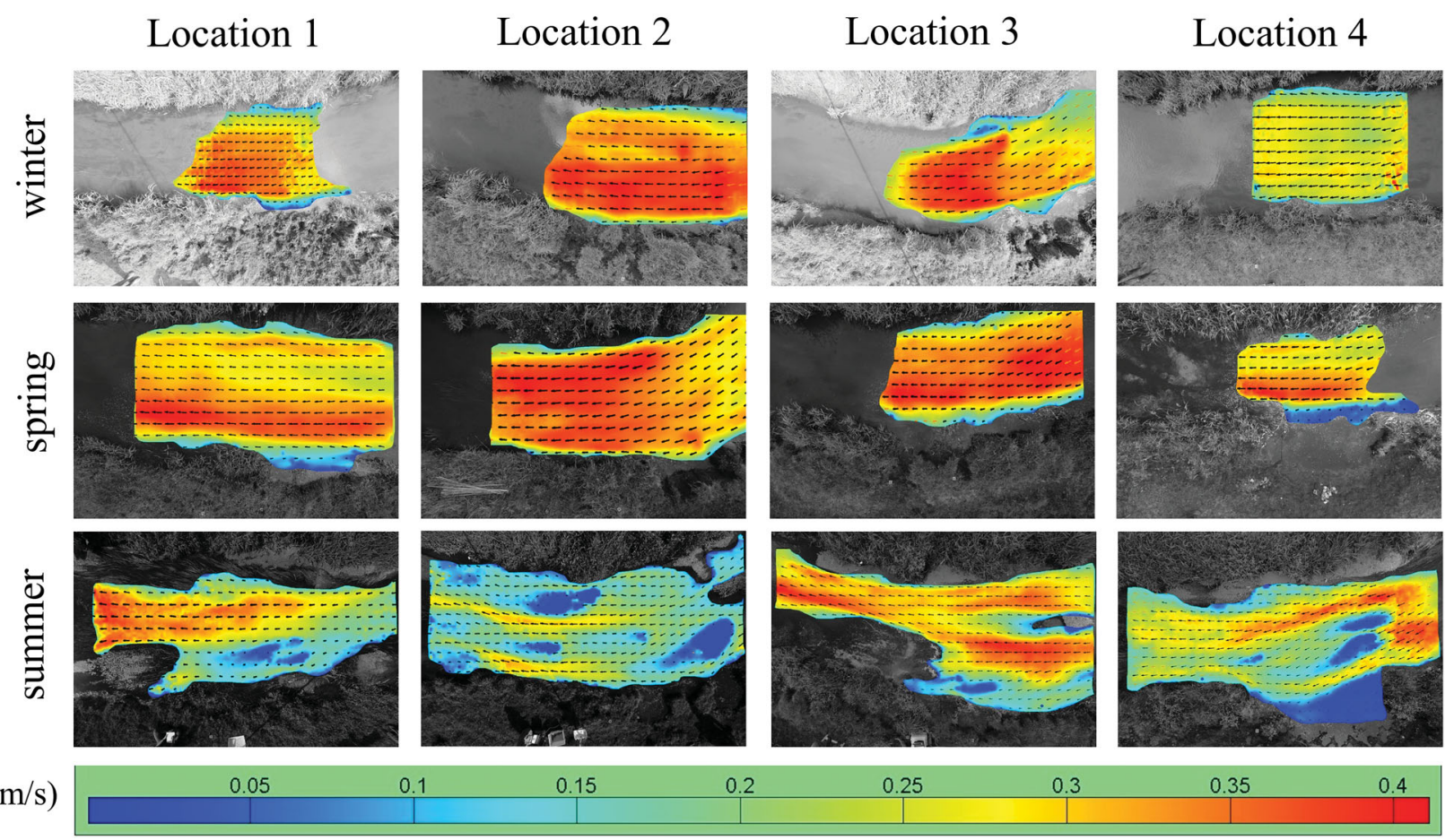

Figure 5. Time average velocity field corresponding with the four locations (L1, L2, L3 and L4) along the Zwarte Nete in winter, spring and summer.

(non-vegetated), spring (submerged vegetation) and summer (floating and submerged vegetation). The panels depicted in Figure 5 summarize the velocity patterns obtained with LSPIV in each season for the ROI selected in each stretch of the river; L1, L2, L3 and L4. It is clear the LSPIV methodology provides high-resolution surface data which allows to analyze the spatial flow pattern distribution. Additionally, locations of high velocity gradients can be located, that result in shear layers and associated increased levels of turbulence and mass exchange. In winter, we observed a homogeneous velocity field with the maximum velocity gradients situated close to the river banks. An average velocity value of $0.30 \mathrm{~m} \mathrm{~s}^{-1}$ (max. velocity $0.38 \mathrm{~m} \mathrm{~s}^{-1}$, min. velocity $0.12 \mathrm{~m} \mathrm{~s}^{-1}$ ) and a measured average discharge of $0.34 \mathrm{~m}^{3} \mathrm{~s}^{-1}$ were calculated from the ECM measurements over the cross section. During spring, submerged vegetation appeared in the main stream, which caused a slight reduction of the mean velocity in these areas. A mean velocity value of $0.31 \mathrm{~m} \mathrm{~s}^{-1}$ was determined (max. velocity $0.33 \mathrm{~m} \mathrm{~s}^{-1}$, min. velocity $0.03 \mathrm{~m} \mathrm{~s}^{-1}$ ), with an average measured discharge of $0.36 \mathrm{~m}^{3} \mathrm{~s}^{-1}$.

The vegetation density reached the maximum in summer, and the flow patterns became highly irregular. Maximum velocities were measured in the free path of the stream, while the lower velocities corresponded with the 
a)

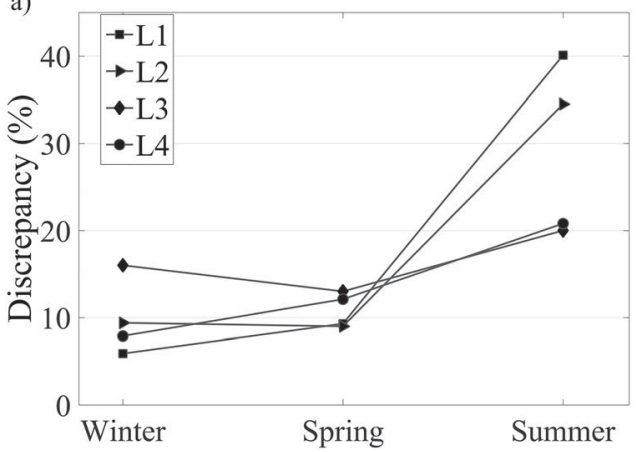

b)

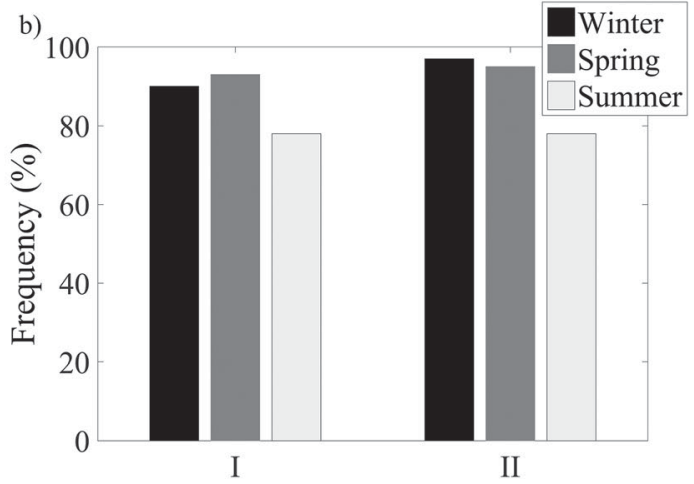

Figure 6. (a) Seasonal variation of the discrepancy observed in each location, (b) frequency histogram of total number of the LSPIV measurements reliable $(R>0)$ for each season. (I) Included all the measurements over the cross sections and (II) the measurements over the cross section where areas without seeding particles are excluded.

location of vegetation patches and stagnant regions close to the river margins. The average measured discharge was $0.25 \mathrm{~m}^{3} \mathrm{~s}^{-1}$ and the measured velocities $0.08-0.40 \mathrm{~m} \mathrm{~s}^{-1}$ (mean value $0.17 \mathrm{~m} \mathrm{~s}^{-1}$ ).

Overall, there was a fluctuation in the velocity SD depending on the season. The discrepancy values showed a maximum in summer (Figure 6(a)). Moreover, different levels of discrepancy were observed at different locations. To unravel the reasons for these variations, in the following section, we analyzed ECM-LSPIV surface velocity profiles for each season in detail. The top panels of Figures 7-9 show the RGB images with field conditions, while the lower panels depict the comparison of the LSPIV and ECM velocity profiles, with associated error bars.
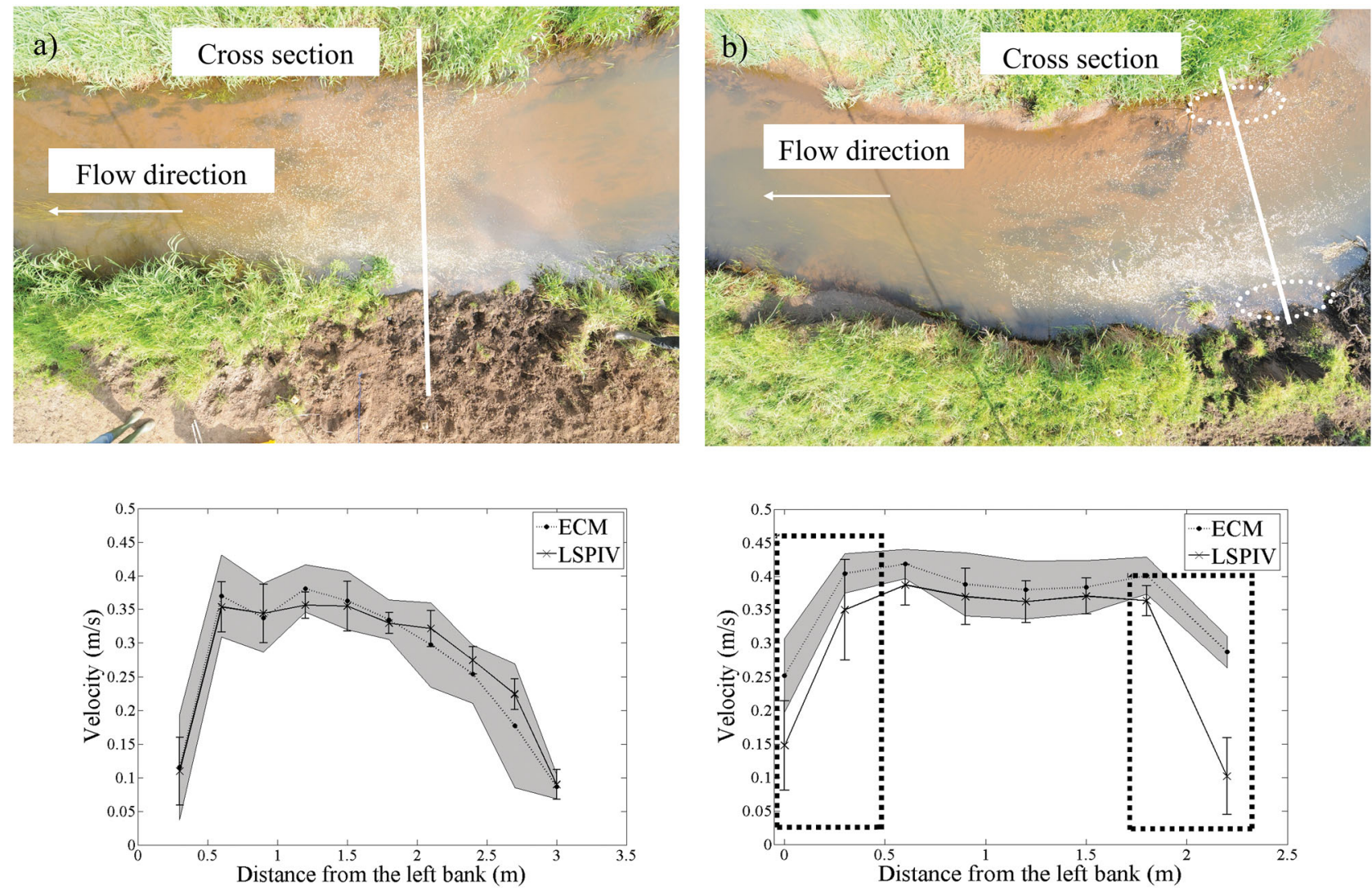

Figure 7. RGB-image of the winter conditions (top panel) and comparison of the mean velocity measurements (lower panel) obtained from ECM and LSPIV over the cross sections. The images cover a distance of $8.5 \mathrm{~m} \times 5.7 \mathrm{~m}$. (a) L1, (b) L3; in the lower panel the dashed lines indicate the areas with no seeding particles. The shadowed area and error bar corresponds with $95 \%$ CI for the ECM and LSPIV measurements, respectively. 

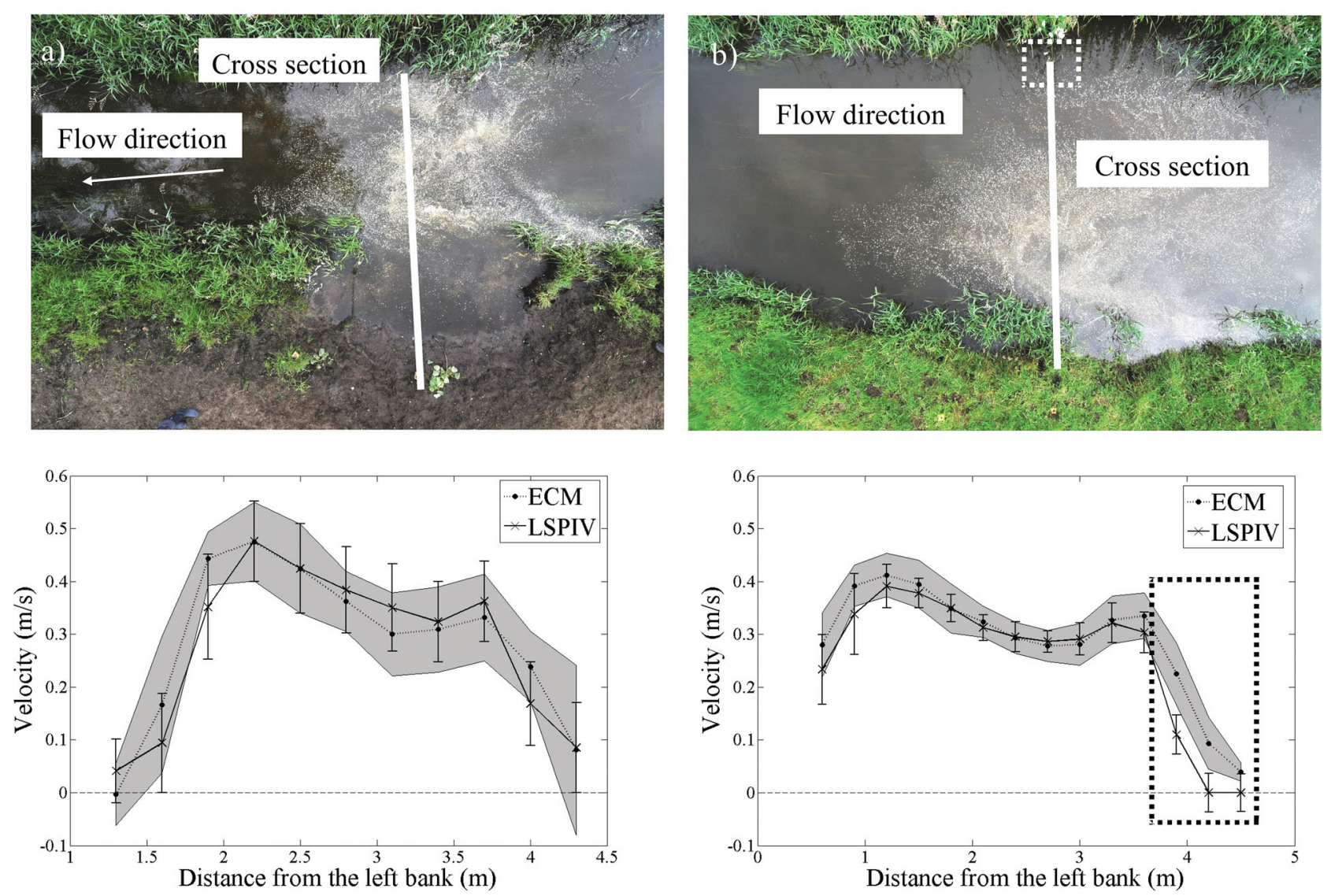

Figure 8. As for Figure 7, spring conditions with locations (a) L4, (b) L1.

\section{Winter}

As can be observed in Figure 7, the winter velocity profile is asymmetric. The maximum velocities are located in the central part of the stream and velocities gradually reduce toward the banks. In general, the ECM-LSPIV agreement obtained during winter is high, with an averaged discrepancy of $9.8 \%$. For instance, Figure 7(a) illustrates the comparison of the ECM-LSPIV measurements at location 1. At this location, $d$ is very low $(5.9 \%)$, where a high-averaged $d(15.9 \%)$ is observed at location 3 , which is caused by the loss of correlation close to the river margins (Figure 7(b), dashed lines), caused by insufficient seeding of particles.

\section{Spring}

During spring, submerged vegetation ( $S$. emersum) appeared floating close to the free surface. The surface velocity profile becomes less homogeneous and slight velocity gradients are observed in the middle of the channel. High values of velocity SD are observed, particularly at location 4, where values rise up to 0.042 and $0.043 \mathrm{~m} \mathrm{~s}^{-1}$ for ECM and LSPIV, respectively.

The comparison of the ECM and LSPIV measurements shows a good correlation along the center part of the channel, where the submerged vegetation is situated. Similar to winter, it is possible to observe high values of $d$ in the river margins. Despite the vegetation occurrence, in spring $d$ is low $(11 \%)$.

\section{Summer}

Compared with winter and spring, the velocity profile (Figure 9) in summer is highly heterogeneous. A clear increase of the discrepancy is observed in summer, particularly noticeable in the areas with high velocity gradients located on the edges of the vegetation patches. For instance, Figure 9(a) depicts a cross section performed through a mixed patch (floating and submerged vegetation) (A), and the wake zone of a second patch (B) (dashed lines). As a result of the loss of agreement, discrepancy along the edges of the patches is higher and $d$ reaches values of up to $40 \%$. In summer, the discrepancy varies over the measuring points along the cross section. For instance, for points situated in the free path of the stream $d(11 \%)$ is similar to the value in winter, while for the points over the vegetation $d$ reaches $84 \%$. Figure 9(b) depicts the average velocity profile at Location 4 , where despite the presence of floating vegetation, $d$ is lower (20\%). An increase of the LSPIV velocity SD is observed in summer, reaching values up to $0.078 \mathrm{~m} \mathrm{~s}^{-1}$. 

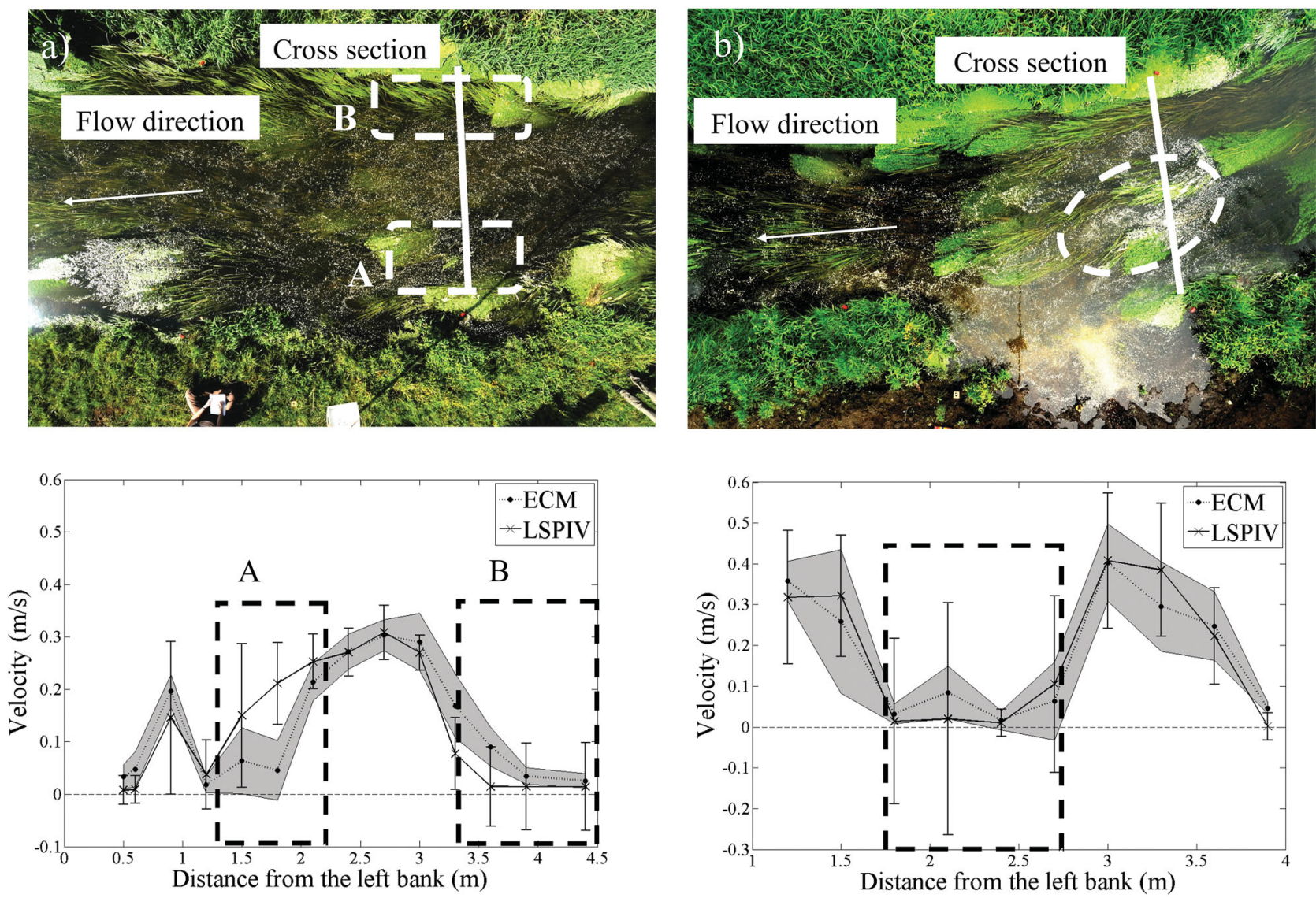

Figure 9. As for Figure 7, summer conditions with locations (a) L1, (b) L4.

\section{LSPIV reliability}

In the previous sections, the LSPIV methodology was compared with the ECM measurements by evaluating the discrepancy between both. However, this result did not account for the velocity SD of each instrument. Therefore, to obtain a measure for the reliability of the method, we consider the SD of the sampling distribution, which is equal to the square root of the sum of each sample variance, see Equation (2). We then consider each LSPIV measurement as reliable when it is enclosed in the confidence interval $(\mathrm{CI})$ of the difference between the LSPIV and the ECM measurement (at 95\% confidence level). In particular,

$$
\begin{aligned}
\mathrm{SD} & =\sqrt{\sigma_{\mathrm{V}, \mathrm{ECM}}^{2}+\sigma_{\mathrm{V}, \mathrm{LSPIV}}^{2}}, \\
r & =\mathrm{CI}-\left|V_{\mathrm{ECM}}-V_{\mathrm{LSPIV}}\right|,
\end{aligned}
$$

and if $r \geq 0$, we consider the LSPIV reliable.

The left bars (I) of Figure 6(b) illustrate the percentage of reliable LSPIV measurements and denote an overall value of the LSPIV reliability. The levels of reliability observed in winter and spring are $90 \%$ and $92 \%$, respectively, while a lower reliability is obtained for summer conditions $(78 \%)$. As indicated by Figures $7-9$, close to the river margins and stagnant areas, the distribution of the seeding particles is insufficient, resulting in areas where no LSPIV data are available. The areas with a shortage of seeding particles are easily recognizable in the RGB images. In the right bars of Figure 6(b) (II), we illustrate the reliability when the parts of the cross section corresponding with these areas were removed. As a result, the frequency of reliable measurements increases up to $97 \%$ in winter and $95 \%$ in spring. However, in summer the high values of discrepancy are in general not following from issues with the seeding density. Hence, all the points over the cross sections were included to calculate the frequency of reliable measurements.

\section{Discussion}

The present study showed the potential of LSPIV as a reliable and fast method to acquire high-resolution and low-cost data at reach scale. The assessment of the reliability was made through the analysis and comparison with ECM measurements. Overall, LSPIV reliability is high ( $97 \%, 95 \%$ and $78 \%$ in winter, spring and summer, respectively). Nevertheless, a temporal and spatial variation of the LSPIV reliability has been found. 
First, it should be noticed that the direct comparison of ECM with LSPIV measurements is not entirely correct, because of the differences in sampling volume. Muste et al. (2011) already argued that this can evoke differences observed between LSPIV and Acoustic Doppler Current Profilers velocity measurements. The ECM measures a $2 \mathrm{~cm}^{3}$ volume at $5 \mathrm{~cm}$ below the surface, while the LSPIV samples a surface of $12.8 \mathrm{~cm} \times 12.8 \mathrm{~cm}$ at the water surface. Hence, a certain level of discrepancy should be expected in a direct ECM-LSPIV measurement comparison.

Nonetheless, we found very high levels of agreement in non-vegetated conditions $(d<10 \%)$. Previous comparisons of velocities obtained with LSPIV in field conditions show errors between $10 \%$ and $35 \%$ in non-vegetated stream (Muste et al. 2004; Kim et al. 2008). We can therefore assert that the LSPIV methodology was successfully implemented and the posterior problems were not following from an incorrect application of the methodology. Here, it should be noted that LSPIV proves to be a valuable measurement technique, but does not replace traditional measurement techniques. For instance, a combination of LSPIV to capture the large flow scales (at the surface) with classical point measurements to obtain more detailed characteristics of the flow can result in a powerful combination of techniques to help understanding the complex flow in vegetated streams and rivers.

Secondly, the difference between ECM and LSPIV measurement depth could have led to a difference in the $\mathrm{SD}$ of the recorded velocities. A clear correlation between the increase of the velocity SD and the vegetation occurrence has been observed. This increase of the measurement deviation is (partially) caused by plant species which perform undulating movements, generating (relatively highly energetic) turbulence (Sand-Jensen \& Pedersen 1999) with large time scales. The maximum deviation for the ECM measurements is observed during spring $\left(0.03 \mathrm{~m} \mathrm{~s}^{-1}\right)$ when submerged macrophytes predominate in the main stream. However, for the LSPIV measurements, the SD reaches the maximum during the summer $\left(0.052 \mathrm{~m} \mathrm{~s}^{-1}\right)$ in coincidence with a high density of floating macrophytes. Therefore, the sensitivity of the techniques to the inherent variability of the flow could be related to the vegetation height (submerged or floating) and depth of measurements. Furthermore, it should be noted that since the ECM is below the water surface, and since dense vegetation could be present, correct alignment of the ECM with respect to the local mean flow direction is difficult to ensure. Therefore, ECM results could suffer from measurement errors due to instrument alignment issues.

Finally, for the LSPIV measurements, three time series of 20 images were recorded in three bursts of $3 \mathrm{~s}$ while the ECM measurement time was $30 \mathrm{~s}$. Hence, a larger uncertainty on the time-averaged value for LSPIV measurements can be expected, when compared with ECM measurements.
A detailed analysis of the results shows a high spatial variability of the LSPIV reliability over the cross section. As can be observed in Figures 7 and 8, the results show higher discrepancies for the points situated close to the river banks. Obtaining the required seeding density is a complex task, especially over stagnant areas or irregular river bank morphology. Hence, an inadequate seeding density is the main reason of discrepancies during winter and spring. Furthermore, during summer, the presence of dense floating vegetation (Figure 9) creates a physical obstruction which blocks the movement of the particles, compromising the LSPIV reliability.

The free-surface velocity fields obtained with LSPIV (Figure 5) clearly shows the increased heterogeneity in flow patterns throughout the seasons. The homogeneous surface velocity distribution observed in winter is altered as a result of the occurrence of submerged vegetation during spring. A stream deceleration is observed in the area occupied by submerged vegetation. The flow is diverted around the vegetation patch, increasing the velocity in the free path of the stream. However, the low shooting density of $S$. emersum allows the flow to penetrate through the patch reducing the impact in the mean velocities (SandJensen 1998).

The heterogeneity continuously increases until the summer, when the percentage of the area covered by vegetation and the range of species is maximum (occurrence of e.g. C. platycarpa, M. spicatum, E. Canadensis). In summer, high velocity gradients are observed for floating macrophytes with high shooting density and low porosity. Reduced velocities are observed at high density areas which leads to stream acceleration alongside the patch (Meire et al. 2012). In these complex flow patterns, LSPIV measures the full magnitude of velocities regardless the flow direction, while ECM measures only the component of the main direction. Therefore, LSPIV shows a great advantage, for instance, to measure the velocity field of the wake areas downstream of the low porosity patches with reversing flow and reduced velocities (Ingo \& Helen 2009).

Flow velocity and discharge are ecologically relevant parameters that can be used as a measure of the relationship between hydraulic resistance caused by the vegetation and the hydraulic capacity of the river (De Doncker et al. 2009). The high heterogeneity observed in vegetated conditions makes aerial cover information necessary in order to have an accurate estimate of the hydraulic resistance. Similarly, the effect of the macrophytes on the vertical velocity profile makes it necessary to obtain the height of the vegetation relative to the water depth. It should be noted, however, that LSPIV only provides surface velocity values. In addition to the LSPIV technique, Visser et al. (2015) shows the possibility of applying optical remote sensing to map submerged vegetation depth. The use of different optical image techniques as a cost-effective method to study plant-flow interaction in rivers is a challenge, but 
the findings presented in this paper show the potential of their applicability.

\section{Conclusion}

The present study describes the LSPIV methodology applied to acquire data in vegetated conditions, and analyzes the reliability of the technique by comparison with ECM measurements. Application of LSPIV to streams with vegetation present proved promising and delivers accurate results, provided some additional precautions are taken such as sufficient care to seeding the flow and removing areas from the analysis where the tracers are blocked by the vegetation, or inadequate seeding density is present. Comparison between ECM and LSPIV velocity measurements shows the complexity to study flow distribution in vegetated streams. Based on the presented analysis, it can be concluded that the major source of discrepancy consists in the inherent limitation of the LSPIV regarding the seeding particle distribution and unsteadiness of the flow. It should also be noted that both techniques measure velocities in different measurement volumes (both in depth and horizontal size), which can be the source for some of the observed differences. Despite that, LSPIV has fundamental advantages compared with classical point measurement. With the current evaluation of the accuracy of the LSPIV methodology to obtain velocity fields in vegetated flow conditions, analysis of the flow features encountered in the field can be performed with a better understanding of the sensitivity of the results for the conditions at hand. Some first results show the promising capabilities of the methodology when applied to vegetated flow at several locations over a growing season, however, further analysis of the flow was outside the scope of this paper. LSPIV proves to be a timecost effective technique that provides results with very high spatial resolution at ecosystem scale. The LSPIV technique can contribute a great amount of detailed data to provide new insight in 2D (eco-) hydraulic phenomena, and how to model them in numerical approaches.

\section{Disclosure statement}

No potential conflict of interest was reported by the authors.

\section{Notes on contributors}

Stéphan Creëlle PhD student at the Department of Civil Engineering, Ghent University, Belgium.

Rebeca Roldan Former PhD student at the Department of Civil Engineering, Ghent University, Belgium.

Anke Herremans Former PhD student at the Department of Civil Engineering, Ghent University, Belgium.

Dr. Dieter Meire is former researcher at the Department of Civil Engineering, Ghent University, Belgium. Presently, he is a researcher at Flanders Hydraulics Research, Belgium.
Kerst Buis Researcher at the Department of Biology, University of Antwerp, Belgium.

Dr. Patrick Meire is professor at the Department of Biology, University of Antwerp, Belgium.

Dr. Tomas Van Oyen is a former post-doctoral researcher at the Department of Civil Engineering, Ghent University, Belgium. Presently, he is a researcher at Flanders Hydraulics Research, Belgium.

Dr. Tom De Mulder is associate professor at the Department of Civil Engineering, Ghent University, Belgium.

Dr. Peter Troch is associate professor at the Department of Civil Engineering, Ghent University, Belgium.

\section{References}

Adrian RJ. 1991. Particle-imaging techniques for experimental fluid-mechanics. Annu Rev Fluid Mech. 23:261-304.

Bal K, Struyf E, Vereecken H, Viaene P, De Doncker L, de Deckere E, Mostaert F, Meire P. 2011. How do macrophyte distribution patterns affect hydraulic resistances? Ecol Eng. 37:529-533.

Bouguet J-Y. 2010. Camera calibration toolbox for MATLAB [Internet]. Available from: http://www.vision.caltech.edu/ bouguetj/calib_doc/, Accessed 24 July 2014.

Bradley AA, Kruger A, Meselhe EA, Muste MVI. 2002. Flow measurement in streams using video imagery. Water Resour Res. 38:51-1-51-8.

Carollo FG, Ferro V, Termini D. 2002. Flow velocity measurements in vegetated channels. J Hydraul Eng. 128:664-673.

Creutin J, Muste M, Bradley A, Kim S, Kruger A. 2003. River gauging using PIV techniques: a proof of concept experiment on the Iowa River. J Hydrol. 277:182-194.

De Doncker L, Troch P, Verhoeven R. 2008. Accuracy of discharge measurements in a vegetated river. Flow Meas Instrum. 19:29-40.

De Doncker L, Troch P, Verhoeven R, Bal K, Desmet N, Meire P. 2009. Relation between resistance characteristics due to aquatic weed growth and the hydraulic capacity of the river Aa. River Res Appl. 25:1287-1303.

Folkard AM. 2011. Vegetated flows in their environmental context: a review. Proc ICEE Comp Mech. 164.

Franklin P, Dunbar M, Whitehead P. 2008. Flow controls on lowland river macrophytes: a review. Sci Total Environ. 400:369-378.

Fujita I, Hino T. 2003. Unseeded and seeded PIV measurements of river flows videotaped from a helicopter. J Vis. 6:245252.

Fujita I, Muste M, Kruger A. 1998. Large-scale particle image velocimetry for flow analysis in hydraulic engineering applications. J Hydraul Res. 36:397-414.

Green JC. 2005. Modelling flow resistance in vegetated streams: review and development of new theory. Hydrol Process. 19:1245-1259.

Hauet A, Kruger A, Krajewski WF, Bradley A, Muste M, Creutin JD, Wilson M. 2008. Experimental system for real-time discharge estimation using an image-based method. J Hydrol Eng. 13:105-110.

Ingo S, Helen LM. 2009. Vegetation and hydraulic-morphological interactions at the individual plant, patch and channel scale. Aquat Sci. 71:318-330.

Jarvela J. 2005. Effect of submerged flexible vegetation on flow structure and resistance. J Hydrol. 307:233-241. 
Jodeau M, Hauet A, Paquier A, Le Coz J, Dramais G. 2008. Application and evaluation of LS-PIV technique for the monitoring of river surface velocities in high flow conditions. Flow Meas Instrum. 19:117-127.

Kantoush SA, Schleiss AJ, Sumi T, Murasaki M. 2011. LSPIV implementation for environmental flow in various laboratory and field cases. J Hydro-env Res. 5:263-276.

Kim Y, Muste M, Hauet A, Krajewski WF, Kruger A, Bradley A. 2008. Stream discharge using mobile large-scale particle image velocimetry: a proof of concept. Water Resour Res. 44:9. doi:10.1029/2006WR005441View.

Leu JM, Chan HC, Jia YF, He ZG, Wang SSY. 2008. Cutting management of riparian vegetation by using hydrodynamic model simulations. Adv Water Resour. 31:12991308.

Meire D, Schoelynck J, Buis K, Troch P, Meire P, Temmerman S. 2012. Flow measurements around a submerged macrophyte patch in an in-situ flume setup. Proc 9th ISE Conf. Vienna.

Meselhe E, Peeva T, Muste M. 2004. Large scale particle image velocimetry for low velocity and shallow water flows. J Hydraul Eng. 130:937-940.

Muste M, Fujita I, Hauet A. 2008. Large-scale particle image velocimetry for measurements in riverine environments. Water Resour Res. 44:4. doi:10.1029/2008WR006950View.

Muste M, Ho HC, Kim D. 2011. Considerations on direct stream flow measurements using video imagery: outlook and research needs. J Hydro-Env Res. 5:289-300.

Muste M, Xiong Z, Schöne J, Li Z. 2004. Validation and extension of image velocimetry capabilities for flow diagnostics in hydraulic modeling. J Hydraul Eng. 130:175-185.

Nikora V, Larned S, Nikora N, Debnath K, Cooper G, Reid M. 2008. Hydraulic resistance due to aquatic vegetation in small streams: field study. J Hydraul Eng. 134:1326-1332.
Poggi D, Krug C, Katul GG. 2009. Hydraulic resistance of submerged rigid vegetation derived from first-order closure models. Water Resour Res. 45:10. doi:10.1029/2008WR007 373View.

Sand-Jensen K. 1998. Influence of submerged macrophytes on sediment composition and near-bed flow in lowland streams. Freshwat Biol. 39:663-679.

Sand-Jensen K, Pedersen O. 1999. Velocity gradients and turbulence around macrophyte stands in streams. Freshwat Biol. 42:315-328.

Smith JC, Bérubé F, Bergeron NE. 2005. A field application of particle image velocimetry (PIV) for the measurement of surface flow velocities in aquatic habitat studies. 26th Canadian Symposium on Remote Sensing; Wolfville (NS).

Stanislas M, Monnier J. 1997. Practical aspects of image recording in particle image velocimetry. MeScT 8:1417.

Stephan U, Gutknecht D. 2002. Hydraulic resistance of submerged flexible vegetation. J Hydrol. 269:27-43.

Sukhodolov A, Sukhodolova T. 2010. Case study: effect of submerged aquatic plants on turbulence structure in a lowland river. J Hydraul Eng. 136:434 446.

Thielicke W, Stamhuis E. 2015. PIVlab- time-resolved digital particle image velocimetry tool for Matlab. Available from: http://pivlab.blogspot.com/, Accessed 8 July 2014.

Van Oyen T, Lanzoni S, D'Alpaos A, Temmerman S, Troch P, Carniello L. 2012. A simplified model for frictionally dominated tidal flows. Geophys Res Lett. 39:L12403.

Visser F, Buis K, Verschoren V, Meire P. 2015. Depth estimation of submerged aquatic vegetation in clear water streams using optical remote sensing. Remote Sens. 15:25287-25312.

Weitbrecht V, Kuhn G, Jirka GH. 2002. Large scale PIVmeasurements at the surface of shallow water flows. Flow Meas Instrum. 13:237-245. 